\title{
Caracterização da drenagem pluvial no Bairro Parque Eldorado, localizado em Porto Nacional (TO)
}

O cenário atual brasileiro, no que diz respeito à drenagem urbana, não é dos melhores. O país passa por problemas que, em sua maioria, foram desencadeados pela forma ineficiente como as cidades se desenvolveram: falta de planejamento; ausência de medidas controladoras para o uso do solo; rigor, quanto à ocupação de áreas de risco; e implantação de sistemas de drenagem inapropriados, o que acaba por gerar significativos problemas sociais. O modelo de drenagem urbana mais usado atualmente no Brasil consiste em coletar as águas pluviais e direcioná-las o mais rápido possível até o seu destino final, que são os cursos d'água, com o intuito de minimizar os problemas causados à sociedade e ao meio ambiente. No Bairro Parque Eldorado, o cenário é parecido, a inexistência de um sistema de drenagem pluvial compromete o bem-estar da população em épocas chuvosas, devido aos constantes alagamentos, enxurradas e erosões do solo, o que afeta diariamente a qualidade de vida. Este trabalho analisa a capacidade de infiltração de água do solo e identifica os pontos mais críticos e os seus principais problemas. Com a finalização da presente pesquisa, foi possível oferecer uma alternativa viável para a destinação das águas pluviais de forma eficiente e prática.

Palavras-chave: Águas; Pluviais; Drenagem.

\section{Rain drainage characterization in the Parque Eldorado neighborhood, located in Porto Nacional (TO)}

\begin{abstract}
The current Brazilian scenario with regard to urban drainage is not the best. The country is experiencing problems that were mostly triggered by the inefficient way in which cities developed: lack of planning; absence of controlling measures for land use; strictness, regarding the occupation of risk areas; and implementation of inappropriate drainage systems, which ultimately generates significant social problems. The most commonly used urban drainage model in Brazil today is to collect rainwater and direct it as soon as possible to its final destination, which is the watercourse, in order to minimize the problems caused to society and the environment. environment. In Parque Eldorado neighborhood, the scenario is similar, the lack of a rain drainage system compromises the well-being of the population in rainy seasons, due to constant flooding, runoff and soil erosion, which affects daily quality of life. This paper analyzes the water infiltration capacity of the soil and identifies the most critical points and their main problems. With the completion of this research, it was possible to offer a viable alternative for the efficient and practical destination of rainwater.
\end{abstract}

Keywords: Waters; Rain; Drainage.

Topic: Engenharia Civil

Reviewed anonymously in the process of blind peer.
Received: 09/04/2019

Approved: 09/07/2019
Francisco Adriano Rodrigues Duarte

Instituto Tocantinense Presidente Antônio Carlos, Brasil http://lattes.cnpq.br/9009681375552369

fran.adriano20@gmail.com

\section{Diogo Pedreira Lima}

Instituto Tocantinense Presidente Antônio Carlos, Brasil

http://lattes.cnpq.br/7967728577417186

diogopedreira@itpac.com.br
Referencing this:

DUARTE, F. A. R.; LIMA, D. P.. Caracterização da drenagem pluvial no Bairro Parque Eldorado, localizado em Porto Nacional (TO).

Engineering Sciences, v.7, n.2, p.20-27, 2019. DOI:

http://doi.org/10.6008/CBPC2318-3055.2019.002.0003 


\section{INTRODUÇÃO}

O crescimento desordenado das cidades foi intensificado nas últimas décadas, devido às migrações internas do país, e principalmente a partir da fuga do homem do campo, que, em busca de melhores condições de vida, saíram da zona rural e na maioria das vezes ocuparam as regiões periféricas das cidades. O desenvolvimento acelerado aliado à falta de planejamento urbano acarretou ao longo do tempo sérios problemas de drenagem das águas pluviais, em resposta à rápida expansão das áreas impermeáveis como os telhados, pavimentação de ruas e calçadas, áreas de estacionamento, que juntos reduzem a infiltração do solo contribuindo para o aumento do escoamento superficial.

De acordo com As Diretrizes Básicas para Projetos de Drenagem Urbana do Município de São Paulo (FCTH, 1999), a falta de Planos Diretores de Drenagem Urbana, que visam solucionar os problemas de drenagem no que diz respeito à bacia hidrográfica, a inexistência de recursos legais e administrativos eficazes, que possibilitem uma gestão acertada das consequências dos processos de urbanização causadas pelas enchentes urbanas e a criação imprópria da maior parte dos projetos de drenagem urbana, colaboram no agravamento da problemática.

Para Silveira et al. (2013), infiltração é caracterizada como a passagem da água da superfície do solo para o seu interior. Este processo é dependente da fração de água disponível para infiltrar, da estrutura do solo, das condições superficiais e da fração de água e ar presentes em seu interior. Durante uma chuva, uma fração da água pode se infiltrar no solo, movendo-se para baixo e a outra porção pode escorrer pela superfície, caso o terreno apresente declividade suficiente. Dessa forma, subentende-se que a infiltração é um sistema que separa a água da chuva em duas frações, visto que uma parte flui sobre a superfície e a outra abaixo da superfície do solo, tanto vertical quanto horizontalmente (LIBARDI, 2005).

Já o coeficiente de escoamento superficial sofre mudanças de acordo com a intensidade da precipitação, uma vez que aumenta a magnitude da precipitação as perdas iniciais assim como a capacidade de infiltração do solo são atendidas, dessa forma há um aumento do escoamento superficial e, consequentemente, um aumento no coeficiente de escoamento superficial (TUCCI, 2000). Peixoto (2002) destaca que, o estágio do escoamento superficial analisa a ocorrência e o deslocamento da água na superfície terrestre, e que grande parte das análises hidrológicas estão voltadas à sua aplicação e proteção contra fenômenos causados pelo seu deslocamento.

Moura (2004) destaca que a elaboração de sistemas de drenagem surge da seleção das opções mais eficazes e viáveis para uma área predefinida. Dessa forma, a definição do sistema a ser adotado leva em consideração diversos fatores intervenientes no meio, que abrangem tanto os aspectos técnicos quanto os ambientais, sociais, políticos, econômicos, sanitários, assim como quaisquer outros que, de acordo com a necessidade se mostrarem importantes.

Através do planejamento urbano e da implantação de obras de infraestrutura é possível diminuir os problemas de drenagem, mas para isso se faz necessário estudos de campo, análises precisas, profissionais devidamente habilitados e interesse político, caso contrário dificilmente esse cenário será revertido. Nesse 
sentido, esse trabalho busca conhecer a capacidade de infiltração de água desse solo, determinar os pontos críticos e indicar qual a solução de drenagem mais eficiente de acordo com as condições locais, para que assim os problemas locais sejam solucionados.

\section{REVISÃO TEÓRICA}

\section{Locais onde foram realizadas as coletas do solo}

Em um momento de forte chuva, fez-se uma visita ao bairro, e assim, foi possível constatar os pontos onde havia a maior concentração de alagamentos, enxurradas, erosões do solo etc.. Esses pontos críticos podem ser observados na figura 1. O solo do 'ponto 1' foi coletado na região sul do bairro com as seguintes coordenadas geográficas: $10^{\circ} 44^{\prime} 00.8^{\prime \prime} \mathrm{S} 48^{\circ} 23^{\prime} 06.3^{\prime \prime} \mathrm{W}$ como mostra figura 2 . 0 solo do 'ponto $2^{\prime}$ foi coletado na extremidade norte do bairro com as seguintes coordenadas geográficas: $10^{\circ} 43^{\prime} 48.6^{\prime \prime} \mathrm{S} 48^{\circ} 23^{\prime} 06.4^{\prime \prime} \mathrm{W}$ como mostra a figura 3. 0 solo do 'ponto 3 ' foi coletado na extremidade leste do bairro com as seguintes coordenadas geográficas: $10^{\circ} 43^{\prime} 54.2^{\prime \prime} \mathrm{S} 48^{\circ} 23^{\prime} 02.0^{\prime \prime} \mathrm{W}$ como mostra a figura 4.

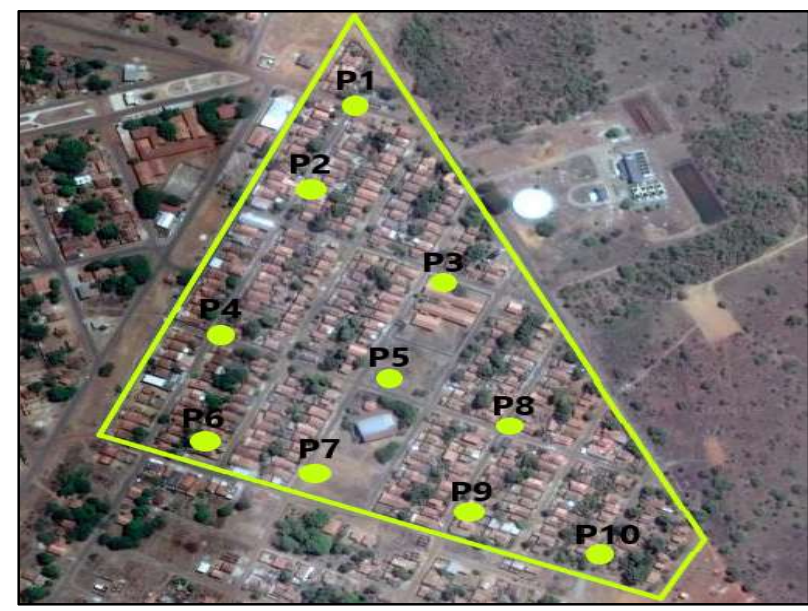

Figura 1: Representação dos pontos críticos.

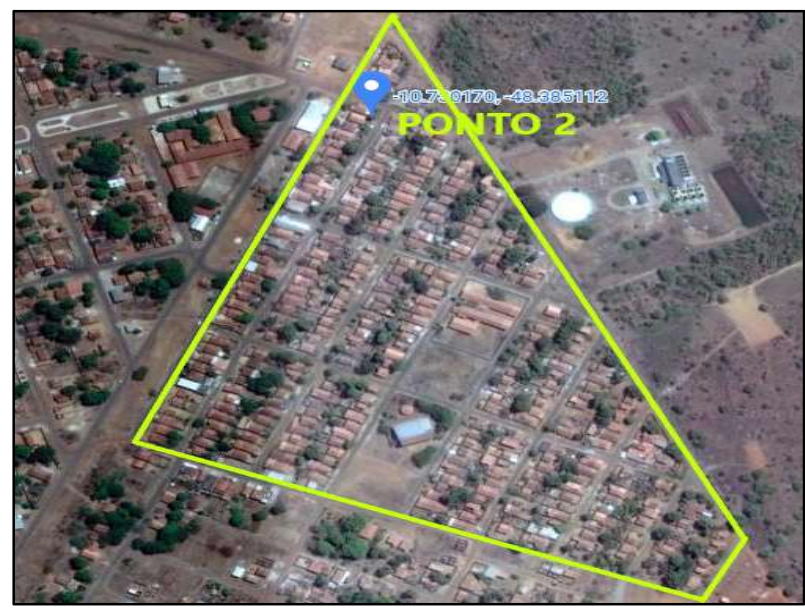

Figura 3: Local de coleta do solo do ponto 2.

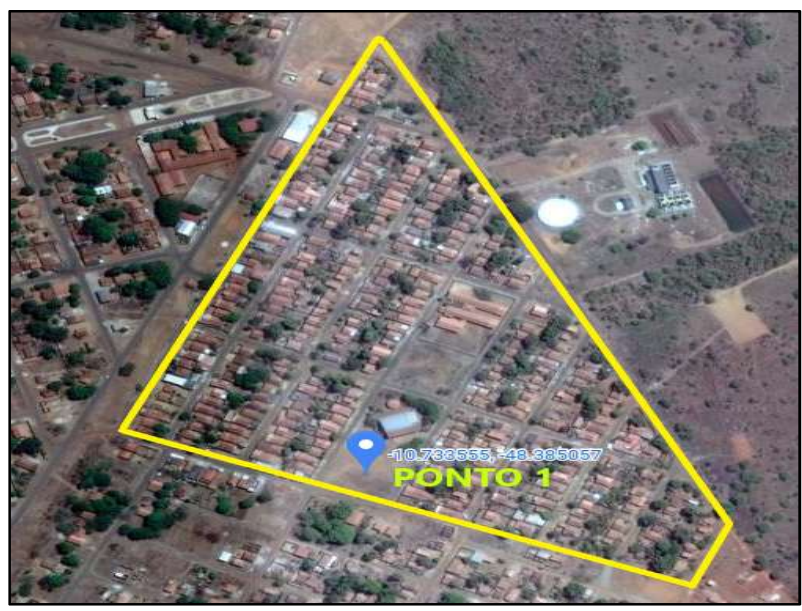

Figura 2: Local de coleta do solo do 'ponto 1.

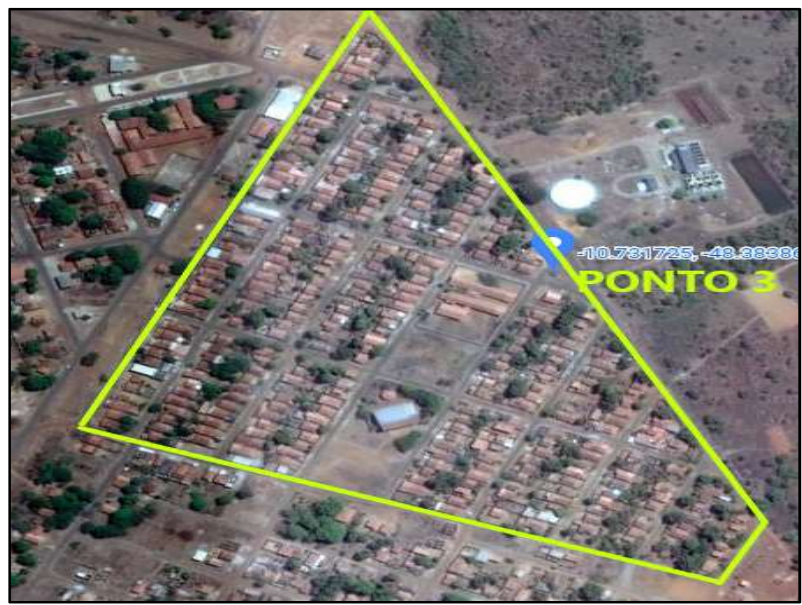

Figura 4: Local de coleta do solo do ponto 3.

\section{Preparação das amostras de solo}

Foram colocados $20 \mathrm{~kg}$ de cada solo para secagem ao ar livre, afim de que atingissem a umidade higroscópica com o meio, após três dias de secagem, os solos estavam prontos para serem destorroados, no 
almofariz com mão de borracha, e peneirados, na peneira $\mathrm{n}$-4 $(4,8 \mathrm{~mm})$. Em seguida, os solos foram armazenados em locais limpos para então serem ensaiados.

\section{Ensaios laboratoriais: compactação normal na energia proctor}

De acordo com a ABNT NBR 7182/2016 para a realização da compactação na energia proctor normal e obtenção da curva de compactação e umidade ótima, inicialmente foram retiradas de cada solo cinco amostras, cada uma pesando exatamente $3 \mathrm{~kg}$. De início, adicionou-se $320 \mathrm{~g}$ de água destilada em cada amostra para a sua homogeneização e obtenção de consistência.

Continuando o processo, o solo já homogeneizado foi inserido no molde cilíndrico pequeno em três camadas iguais, cada uma cobrindo aproximadamente um terço do molde, aplicando em cada uma delas 26 golpes distribuídos uniformemente sobre a superfície da camada, com o soquete caindo de uma altura de 0,305m. Ao findar a aplicação dos golpes, removeu-se o colarinho e a base, aplainou-se a superfície do material à altura do molde e pesou-se o conjunto cilindro + solo úmido compactado. Com o auxílio de um extrator, removeu-se a amostra do molde, e partindo-a ao meio coletou-se uma amostra para determinação da umidade.

\section{Massa específica}

Em primeiro lugar realizou-se a pesagem de cada recipiente (tara), e anotado os seus valores. Em seguida, fez-se as pesagens das amostras de solo retiradas do interior de cada corpo de prova (solo + tara), afim de obter-se o valor do seu peso ainda úmido, para só então, serem colocados na estufa por um período de vinte e quatro horas, de modo que toda a umidade presente nesse solo fosse perdida. Após vinte e quatro horas na estufa, as amostras foram retiradas e pesadas uma a uma, constatando-se uma diminuição do peso, uma vez que, toda a umidade havia sido perdida no processo de secagem. Nesse ponto, obteve-se o resultado (sólido + tara). Subtraindo dessa equação o peso da tara, chegou-se ao peso do solo em estado seco.

\section{Permeâmetro de carga variável}

Realizou-se este ensaio de acordo com a ABNT NBR 14545/2000 Determinação do coeficiente de permeabilidade de solos argilosos a carga variável. Para a realização deste ensaio foram seguidas as seguintes etapas: Produção do corpo de prova através da compactação; Impermeabilização da superfície lateral do corpo de prova com parafina, para evitar a fuga lateral da água para fora do mesmo; Colocação da pedra porosa na base do permeâmetro; Colocação do papel filtro acima da pedra porosa para evitar o carreamento de finos para o interior do mesmo; Inserção do corpo de prova precisamente acima do papel filtro; Preenchimento do espaço lateral entre o corpo de prova e as paredes do permeâmetro com argila betonítica, até a altura da amostra para evitar a passagem de água por esse espaço; Posicionamento da tela metálica acima do corpo de prova.

Em continuidade, Colocação de uma camada de areia grossa, preenchendo a parte superior do sistema; Fechamento da tampa superior e posteriormente a travagem dos parafusos; Introdução de água 
limpa e filtrada na parte inferior do permeâmetro até atingir a estabilidade; e Introdução de água limpa e filtrada na parte superior do permeâmetro até atingir a estabilidade. A partir daí, iniciou-se o ensaio onde foram feitas leituras da bureta de dez em dez minutos e posteriormente de uma em uma hora, marcando-se o tempo gasto e a quantidade de água percolada no corpo de prova.

\section{METODOLOGIA}

Este trabalho destaca uma área de estudo, localizada no setor Parque Eldorado, no município de Porto Nacional (TO). O presente trabalho faz parte de um projeto complexo que abrange estudos sobre a drenagem dessa cidade com intuito de contribuir na identificação da capacidade de absorção de água do solo.

A metodologia utilizada consiste na identificação da capacidade de infiltração de água do solo. Para isso, fez-se necessário uma subdivisão relativa à coleta, preparação e caracterização das amostras coletadas em pontos distintos nesse mesmo bairro, para serem ensaiadas conforme os materiais e métodos existentes no laboratório do ITPAC-Porto. Após a coleta dos solos de três diferentes pontos, foram separadamente destorroados, peneirados, espalhados em um ambiente previamente limpo, estando assim expostos para secagem ao ar livre, de forma que chegassem ao equilíbrio higroscópico com o meio ambiente. Após seu acondicionamento, estava apto para ser utilizado nos ensaios laboratoriais. Os ensaios realizados foram os seguintes: compactação na energia proctor normal, determinação da massa específica, e por fim o ensaio do permeâmetro de carga variável.

\section{RESULTADOS}

Toda obra de engenharia deve ser fundamentada em princípios técnicos que visem garantir estabilidade, conforto e segurança, para isso, se faz necessário a realização de estudos do meio em que tal obra se realizará. A partir dos ensaios feitos separadamente para cada ponto, obteve-se os resultados da curva de compactação e do coeficiente de permeabilidade de cada solo. Esses dados são essenciais para o conhecimento das características físicas do solo em questão, garantindo assim maior qualidade e segurança.

Através do ensaio de compactação normal na energia proctor do solo do ponto 1 , encontrou-se uma massa específica aparente seca $(\rho d)$ de $1,78 \mathrm{~g} / \mathrm{cm}^{3}$ e uma umidade ótima ( $w_{\text {ót }}$ ) de 17,6\%. De posse desses dados foi feito o ensaio de permeabilidade no permeâmetro de carga variável obtendo-se um coeficiente de permeabilidade (K), de $5,7 \times 10^{-7} \mathrm{~cm} / \mathrm{s}$. A figura 5 demonstra a curva de compactação do solo do ponto 1 .

A partir dos ensaios realizados com o solo do ponto 2 , encontrou-se uma massa específica aparente seca $(\rho d)$ de $1,790 \mathrm{~g} / \mathrm{cm}^{3}$ com umidade ótima ( $w_{\text {ót }}$ ) de 17,4\%. De posse desses dados foi feito o ensaio de permeabilidade no permeâmetro de carga variável obtendo-se um coeficiente de permeabilidade (K), de $2,2 \times 10^{-5} \mathrm{~cm} / \mathrm{s}$. A curva de compactação do solo do ponto 2 pode ser observada na figura 6 .

A massa específica aparente seca ( $\rho d$ ) obtida nos ensaios com o solo do ponto 3 foi de $1,600 \mathrm{~g} / \mathrm{cm}^{3}$, e a umidade ótima ( $w_{\text {ót }}$ ) alcançada foi de $20,0 \%$. Posteriormente, fez-se o ensaio de permeabilidade no permeâmetro de carga variável obtendo-se um coeficiente de permeabilidade (K), de $4,8 \times 10^{-6} \mathrm{~cm} / \mathrm{s}$. A curva 
de compactação obtida está ilustrada na figura 7. A figura 8 demonstra, segundo A. Casagrande e R. E. Fadum, os intervalos de variação de $\mathrm{K}$ para os diferentes tipos de solos.

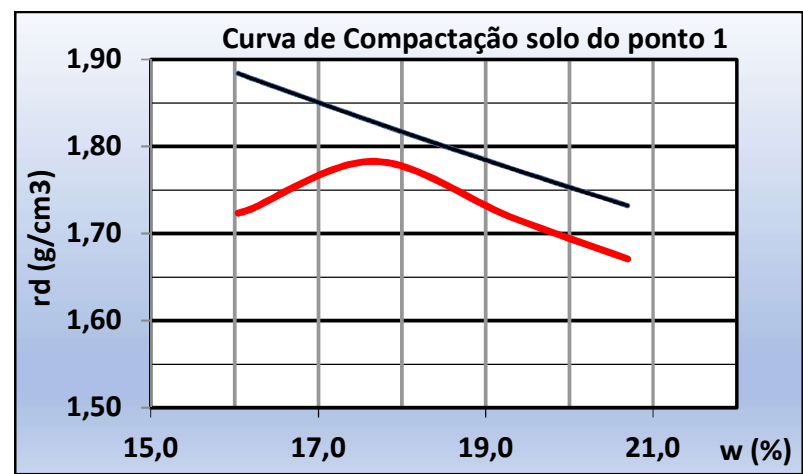

Figura 5: Curva de compactação do solo.

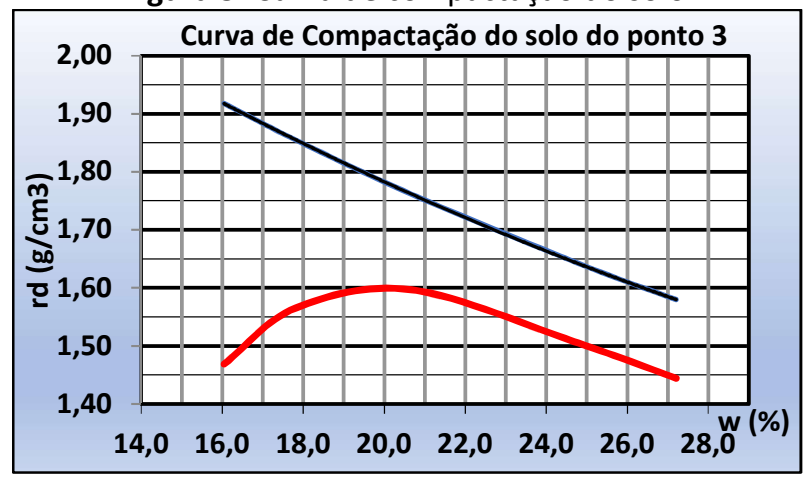

Figura 7: Curva de compactação do solo.

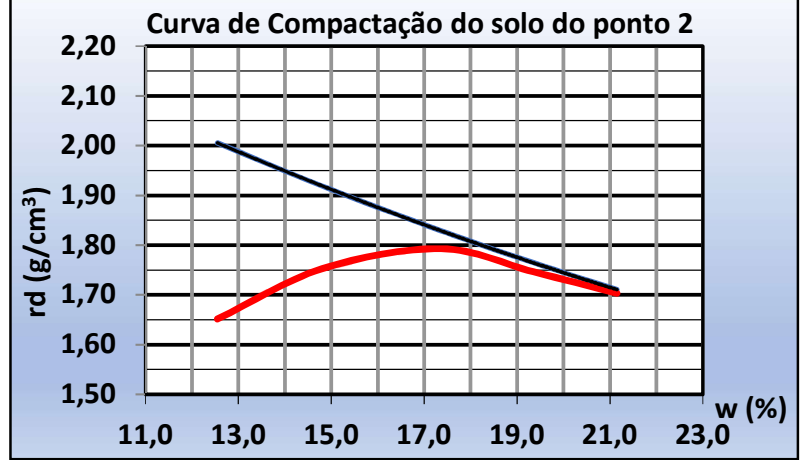

Figura 6: Curva de compactação do solo.

\begin{tabular}{|c|c|c|c|}
\hline $10^{2} \quad 10$ & $10^{-2}$ & $10^{.4} \quad 10^{-6}$ & $10^{.8}$ \\
\hline PEDREGULHO & AREDA & $\begin{array}{l}\text { AREA MUTO TINASE } \\
\text { SLTES,MITTRADE } \\
\text { AMBOSEARGLA }\end{array}$ & ARGLA \\
\hline
\end{tabular}

Figura 8: Intervalos de variação de K para diversos solos.

\section{DISCUSSÃO}

Os coeficientes de permeabilidade (K), dos solos dos três pontos, os classificam como uma areia muito fina e silte, ou ainda como uma mistura de ambos e argila. Solos com essa classificação granulométrica possuem baixa permeabilidade, ou seja, a água demora mais tempo para percolar no meio poroso. Em um projeto de drenagem pluvial abril de 2017 determina que a constituição do solo da bacia em questão é predominantemente argilossiltosa o que lhe confere sob aspecto hidrológico, um elevado potencial de escoamento superficial. Associado a isso, a urbanização extensiva em termos territoriais levou a um alto grau de impermeabilização do solo, o que juntos desencadearam uma série de problemas estruturais e ambientais. Nesse sentido, uma série de medidas foram tomadas, com destaque às obras de micro e macrodrenagem.

Conforme as Diretrizes Básicas para Projetos de Drenagem Urbana do Município de São Paulo (FCTH, 1999), o processo de impermeabilização dos solos causado pelo crescimento desordenado das cidades, gera problemas que em sua maioria podem ser eficientemente tratados com obras de engenharia. Nesse sentido, a diminuição das áreas impermeabilizadas, a implantação de obras de micro e macrodrenagem e a criação de áreas verdes contribuem na redução do escoamento superficial e favorecem o processo de infiltração.

Balduino et al. (2018) determinam que, no período de janeiro de 1997 a dezembro de 2016 o balanço hídrico climatológico de Porto Nacional obteve uma média anual de 1563,16mm de precipitação nos quase 20 anos de estudo, sendo que os períodos chuvosos que vão de outubro a abril contribuem com cerca de $94 \%$ do volume anual de chuva. 
Nos períodos com chuvas de maiores intensidades, devido à baixa permeabilidade do solo causada em parte pelas suas características físicas e também, pela construção de pavimentos e calçadas, a água impedida de percolar, fica mais tempo na superfície, promovendo o escoamento superficial ou ainda os pontos de alagamento no bairro. Através dos resultados obtidos nos ensaios laboratoriais, constata-se a dificuldade do solo local no que tange a drenagem natural das águas pluviais, por esse motivo, e tendo em vista os problemas gerados pelas precipitações de forte intensidade na região, faz-se necessário a implantação de um sistema de drenagem que venha contribuir na coleta e transporte dessa água, de forma eficiente, para um corpo d'água receptor, diminuindo assim, as ocorrências de erosões, alagamentos e enxurradas.

Levando em consideração o tamanho da área a ser atendida, o custo-benefício, a disponibilidade de materiais, a qualificação da mão de obra local e o tempo de execução, as tecnologias mais adequadas para serem implantadas na região são a construção de: Tubulação: tubos cilíndricos de concreto armado cuja função é fazer o direcionamento da água coletada nas bocas de lobo; Bocas de lobo: incumbidas de coletar uma parcela das águas que escoam nas sarjetas e transportá-las para as galerias; e Sarjetas: são faixas em paralelo ao meio fio cuja finalidade é conduzir as águas que caem nas ruas.

Atualmente dispõe-se de inúmeras alternativas capazes de atender essa demanda, com variedade de produtos e serviços. Para este trabalho, tendo em vista a logística da região, os materiais e métodos construtivos e a disponibilidade da mão de obra, a solução proposta atende com eficiência e satisfatoriedade a demanda da região uma vez que se trata de uma alternativa economicamente viável, ecologicamente sustentável e socialmente correta.

\section{CONCLUSÕES}

Com a implantação das obras de engenharia propostas nesse trabalho, será possível reverter esse cenário, minimizando significativamente os problemas causados pelas águas pluviais tais como enxurradas, alagamentos e erosões do solo, devolvendo assim a dignidade da população local, o que acaba por melhorar sua qualidade de vida. Portanto, através dos estudos realizados, constatou-se a necessidade de intervenção técnica na área, com implantação de obras de engenharia, a fim de promover o escoamento das águas pluviais, uma vez que o solo se mostrou incapaz de drenar com eficiência a água oriunda das chuvas, o que resulta em escoamento superficial e diversos pontos de alagamento como constatado no local.

\section{REFERÊNCIAS}

BALDUINO, Â. R.; LIMA, D. P.. Balanço hídrico e classificação climática da cidade de Porto Nacional-TO. Porto Nacional: 2018.

CAPUTO, H. P.. Mecânica dos solos e suas aplicações. 6 ed. Rio de Janeiro: LTC, 1988.

FCTH. Fundação Centro Tecnológico de Hidráulica. Diretrizes Básicas para Projetos de Drenagem Urbana no Município de São Paulo. São Paulo: FCTH, 1999.
LIBARDI, P. L.. Dinâmica da água no solo. São Paulo: EDUSP, 2005.

MOURA, P. M.. Contribuição para a Avaliação Global de Sistemas de Drenagem Urbana. Dissertação (Mestrado em Saneamento, Meio Ambiente e Recursos Hídricos) Universidade Federal de Minas Gerais, Belo Horizonte, 2004.

PEIXOTO, P. P. P.. Bases para aproveitamento e gerenciamento de recursos hídricos na região de Dourados- 
MS. Tese (Doutorado em Agronomia) - Universidade Estadual Paulista 'Júlio de Mesquita Filho', Botucatu, 2002.

RIBEIRO, A. M.. BMP'S em drenagem urbana- aplicabilidade em cidades brasileiras. Dissertação (Mestrado em

Engenharia Hidráulica e Ambiental) - Universidade de São Paulo, São Paulo, 2014.

SILVEIRA, A. L. L.; LOUZADA, J. A. B.; LAWSON, F.. Ciclo Hidrológico e Bacia Hidrográfica. In: TUCCI, C. E. M..
Hidrologia: Ciência e Aplicação. 4 ed. Porto Alegre: EDUFRGS, 2013.

TUCCI, C. E. M.. Aspectos institucionais do controle das inundações urbanas. Centro-Oeste, Brasília, v.1, p.1-16, 1999.

TUCCI, C. E. M.. Coeficiente de escoamento e vazão máxima de bacias urbanas. Revista Brasileira de Recursos Hídricos, Porto Alegre, v.5, n.1, p.61-68, 2000.

A CBPC - Companhia Brasileira de Produção Científica (CNPJ: 11.221.422/0001-03) detém os direitos materiais desta publicação. Os direitos referem-se à publicação do trabalho em qualquer parte do mundo, incluindo os direitos às renovaç̃ões, expansões e disseminações da contribuição, bem como outros direitos subsidiários. Todos os trabalhos publicados eletronicamente poderão posteriormente ser publicados em coletâneas impressas sob coordenação da Sustenere Publishing, da Companhia Brasileira de Produção Científica e seus parceiros autorizados. Os (as) autores (as) preservam os direitos autorais, mas não têm permissão para a publicação da contribuição em outro meio, impresso ou digital, em português ou em tradução. 